EDITORIAI

\title{
Facets of integration in the theory and practice of clinical psychology
}

\author{
Lidia Cierpiatkowska
}

Adam Mickiewicz University in Poznan, Poland

C linical psychology is a field of theory, research and practice that is currently developing very rapidly due not only to new original assumptions that have emerged in traditional paradigm approaches such as psychoanalysis, cognitive and humanistic psychology, but also through the development of innovative integration concepts. At the turn of the twentieth and twenty-first century new models emerged in clinical psychology that describe or explain the mechanisms and determinants of mental health, as well as previously unknown procedures of psychological and psychotherapeutic interventions. Clinical psychology seems to be dominated by concepts that integrate knowledge from various social science disciplines (Cierpiałkowska \& Sęk, 2015, 2016). While some recently created models explaining the functioning of the individual are subject to different empirical verifications, previously unknown treatment strategies and procedures are often applied without prior research, and without further reflection on the appropriateness and relevance of their use (Prochaska \& Norcross, 2006; Brzezinski, 2017).

Emerging new propositions in the theory and practice of clinical psychology have led to reflections on several issues, two of which seem particularly interesting: Firstly, what transformations are a natural consequence of the development of clinical theory and practice within a particular paradigm, and which reflect the integration of assumptions originating from various psychological concepts? Secondly, what new ideas are brought to psychological theory, practice, diagnosis and psychotherapy by the trend for evidence-based practice, which for researchers has become a source of ideas for the development of transtheoretical models describing and explaining human behaviour, and for clinical practitioners a determinant of their usefulness in treating individuals with specific problems and mental disorders.

The development of psychological theory, according to Dan P. McAdams (1994), occurs when its assumptions are more cohesive, versatile and simple, empirical and useful in practice. These indicators of the correctness of a direction and the scope of changes in different concepts are supplemented by the author by one more criterion: their creative potential, expressing the possibility of further development of a particular theory. When psychological theory describes an increasingly broad spectrum of mental health phenomena, explaining also their pathomechanisms and sources of development, then new diagnostic tools and procedures for psychological and psychotherapeutic interventions appear more frequently. As already mentioned, more research is devoted not so much to analysing the directions of development of traditional paradigms, as conceptualisations integrating the assumptions of many concepts with different theoretical roots.

The concept of integration in psychology is understood in a very heterogeneous and ambiguous way, which makes it difficult to discuss the explanatory value of the models and to assess their relevance and usefulness in clinical practice. Integration is generally about different ways of "compiling", "integrating elements into a whole", "fitting", "comple- 
menting and unifying”, etc. This combining occurs at the theoretical level and at the level of clinical practice, especially psychotherapeutic. The necessity of these actions is usually justified by the "failure" of existing concepts or the lack of efficiency and/or too high costs of existing treatment procedures and strategies. The effects of these activities allow some basic ways of integration to be distinguished, which were mostly initiated by psychotherapists but also by researchers and theoreticians in psychology. Most often, there are four ways to integrate:

Theoretical integration consists in combining the assumptions of the basic concept, e.g. psychoanalysis, with new observations or treatment interventions derived from a different paradigm, e.g. behaviourism. A classic example is integrative relational psychotherapy by Paul L. Wachtel (1991, 2008), in which the author combined the assumptions of psychoanalysis with the theses of behaviourism in both explaining the pathomechanism of mental disorders and in treatment strategies.

Assimilative integration consists in the selective incorporation into the theses of a concrete paradigm of findings coming from a different paradigm. However, if in the case of theoretical integration there is a similarity between the theses of different paradigms, in the case of assimilation integration different assumptions are combined, notwithstanding their consistency with the theses of the primary school (Messner, 2001; Drat-Ruszczak, 2016). An example may be models and therapeutic techniques belonging to a third wave of cognitive-behavioural therapy (Hayes, 2004).

Integration based on common factors in psychotherapy emphasises the importance not so much of specific factors as those related to the common aspects of the process, relationship, and therapeutic covenant. An example of one of the first models based on the importance of common factors is the transtheoretical model of the process and stages of treatment of James Prochaska and Carlo DiClemente (1982), developed in Poland by Czesław Czabała (2007).

Eclectic integration consists in the formal linking of various phenomena and strategies of assistance, and the integration of techniques and intervention strategies. Such a path of integration is advocated by Arnold Lazarus, who developed treatment programmes for people with various mental disorders, including strategies from multiple therapeutic schools (Messner, 2001).

The first three ways of integrating therapeutic strategies and techniques, as opposed to the eclectic approach, are also attempting to point to the validity of their linkage at a theoretical level, particularly in explaining the genesis and pathomechanism of psychiatric disorders or the processes of change in psychotherapy. One other way of integrating knowledge is what I call empirical integration, which consists in the development of transtheoretical and transdiagnostic models derived from general and fundamental psychology. These concepts are focused not so much on symptoms as on psychological processes that are the relationships between the genetic, neurobiological and environmental determinants of mental health (Cuthbert, 2014).

The $2^{\text {nd }}$ National Conference on Clinical Psychology in Poznan, entitled "Facets of integration in the theory and practice of clinical psychology", was devoted to issues of integration in theory, diagnosis and psychological health counselling. The papers are the result of the reflections and conceptualisations of clinical researchers and practitioners. The first three papers are more general, focusing on the ways of integrating knowledge in clinical psychology at the theoretical and empirical level, while the remaining papers are about the current conceptualisation of selected mental disorders and behaviour.

The authors of the paper Evidence-based assessment in a transtheoretical and paradigmatic approach assumed that the principles and standards of clinical practice defined in EBP have led to the emergence of many transtheoretical models, but have also significantly influenced the credibility of paradigm practice. Special attention was given to reflections on non-standard clinical situations in diagnostic procedures and the impact of EBP principles on making diagnostic decisions for people with mental health problems. They show how the integration of patient data is used by the clinical psychologist in a transtheoretical and paradigmatic approach in assessment and case formulation in personality disorders.

Jerzy M. Brzezinski also looks at the issue of integration, assuming that there is no meaningful and ethical clinical practice outside of the context of proven empirical theory. The paper Data integration levels. Between scientific research and professional practice in clinical psychology consists of two parts. The first part deals with the methodological peculiarities of the relationship: empirical theory - test of the theory - professional practice from the perspective of EBA and EBPP standards. The second part focuses on the characteristics of the variety of data that a clinician uses in his/her work (scientific and practical) and the problems associated with their integration. It distinguishes four levels of data integration, discussing the importance of theory at the stage of constructing variables and defining the hypothetical relationships between them, their operationalisation and quantitative and qualitative interpretation.

Ewa Trzebińska's paper Emotional health: on the applicability of affective science to the integration of clinical psychology is devoted to the concept of emotional health and its integrative potential in the field of clinical psychology. It is a well-known fact that the transdiagnostic approach and psychotherapy integration, the two most influential integrative move- 
ments in clinical psychology, constitute a search for a sound conceptual foundation of the efforts to organise a plethora of theories and data relating to the psychological aspects of physical and mental health. After discussing some of the assumptions and discrepancies between transdiagnostic and integrative approaches in clinical psychology, the author presents a transtheoretical model of emotional health as well as the possibilities and limitations associated with its use in clinical practice.

The next three papers are devoted to current thinking about mental disorders and clinical practice, especially the diagnosis of adults, children and adolescents with various mental and behavioural disorders.

Beata Pastwa-Wojciechowska's paper Personality disorders and the risk of violating legal norms - what we know about the complex nature of humans addresses issues concerning the relationship between personality disorders and aggression and violence. By analysing different concepts and models, the links between theoretical knowledge about the psychology of personality disorders and its practical application in the area of justice are discussed. Thanks to an analysis of the relationships between the clinical picture of individual types of personality disorders and the psychological concepts that explain their determinants, the disposition of individuals to impulsive and aggressive behaviours is revealed.

Sensory integration disorders, also known as sensory processing disorders (SPD), are often diagnosed in children, although they have not been listed in DSM-5 (APA, 2013). Aneta Borkowska in her paper Sensory processing disorder - diagnostic and therapeutic controversies describes various diagnostic dilemmas of a clinical psychologist associated with the heterogeneities of the clinical picture of these disorders and explains the reasons for the ineffectiveness of occupational therapy. An analysis of the literature shows that the symptoms of sensory processing disorders may be specific and appear in isolation and may be a non-specific element of the clinical picture of others somatic disease and mental disorders. The author emphasises that only an accurate clinical diagnosis can increase the chance of children receiving effective therapy.

The last paper, Behavioural addictions in children and adolescents, by Iwona Grzegorzewska, deals with the very current and important issue of clinical behavioural addictions in children and adolescents. A review of research on the clinical symptoms of addictive behaviour during these developmental periods shows that we do not have sufficient data to allow reliable diagnosis. Also, the diagnostic criteria to distinguish between harmful and pathological behaviours are unclear. Empirical analyses show that the early symptoms of addictive behaviour are a significant threat not only to the mental health of children and adolescents, but also in adulthood.
Currently in clinical psychology - theory and practice - attempts are being made to integrate various psychological concepts and professional experiences in both diagnosis (assessment and case formulation) and the strategy of health counselling. The effects of these activities should be subject not only to theoretical reflection, but also to continuous empirical verification. The papers presented in this issue of CIPP show the directions of these reflections in Polish clinical psychology.

\section{References}

American Psychiatric Associations. (2013). Diagnostic and statistical manual of mental disorders ( $5^{\text {th }}$ ed.). Arlington, VA: American Psychiatric Publishing.

Brzeziński, J. M. (2017). Data integration levels. Between scientific research and professional practice in clinical psychology. Current Issues in Personality Psychology, 3, 163-171.

Cierpiałkowska, L., \& Sęk, H. (2015). Wyzwania dla psychologii klinicznej XXI wieku [Challenges for clinical psychology in the XXI century]. Nauka, 2, 69-85.

Cierpiałkowska, L., \& Sęk, H. (2016). Naukowe i społeczne wyzwania dla psychologii klinicznej [Scientific and social challenges for clinical psychology]. Roczniki Psychologiczne, 19, 406-436.

Cuthbert, B. N. (2014). The RDoC framework: facilitating transition from ICD/DSM to dimensional approaches that integrate neuroscience and psychopathology. World Psychiatry, 13, 1, 28-35. doi: 10.1002/wps.20087

Czabała, C. (2007). Czynniki leczace w psychoterapii [Treatment factors in psychotherapy]. Warszawa: Wydawnictwo Naukowe PWN.

Drat-Ruszczak, K. (2016). Czy teoria kliniczna jest w psychoterapii potrzebna i czym dla niej jest: Rozważania o integracji psychoterapii [Is clinical theory needed in psychotherapy and what purpose does it serve? Reflections on psychotherapy integration]. Roczniki Psychologiczne, 19, 469-517.

Hayes, S. C. (2004). Acceptance and Commitment Therapy, Relational Frame Theory, and the third wave of behavior therapy. Behavior Therapy, 35, 639-665.

McAdams, D. P. (1994). The person: An Introduction to personality psychology. Forth Worth: Hartcourt Brace Colledge Publishers.

Messer, S. B. (2001). Introduction to the special issue on assilmilative integration. Journal of Psychotherapy Integration, 11, 1, 1-4. doi: http://dx.doi.org/ 10.1023/A:1026619423048

Prochaska, J. O., \& DiClemente, C. C. (1982). Transtheoretical therapy: Toward a more integrative model of change. Psychotherapy: Theory, Research, and Practice, 19, 276-288. 
Prochaska, J. O., \& Norcross, J. C. (2006). Systemy terapeutyczne. Analiza trans teoretyczna [Systems of psychotherapy. A transtheoretical analysis]. Warszawa: Instytut Psychologii Zdrowia PTP.

Wachtel P. L. (1991). From eclectism to synthesis: Toward a more seamless psychotherapic integration. Journal of Psychotherapy Integration, 1, 43-54.

Wachtel, P. L. (2008). Relational theory and the practice of psychotherapy. New York, NY: Guilford Press. 